\title{
Çocukluk Çağı Baş Ağrılarında Kranial Manyetik Rezonans Görüntülemenin Tanısal Değeri
}

\author{
Value of Cranial Magnetic Resonance Imaging in Childhood \\ Headaches
}

Ayşe Seçil EKŞiOĞLU¹, Berna UÇAN², Nesrin CEYLAN³

1Sağlık Bilimleri Üniversitesi, Ankara Şehir Hastanesi, Çocuk Hastanesi, Çocuk Radyoloji Kliniği, Ankara, Türkiye

${ }^{2}$ Sağlık Bilimleri Üniversitesi, Dr. Sami Ulus Kadın Doğum, Çocuk Sağlığı ve Hastalıkları Eğitim ve Araştıma Hastanesi, Çocuk Radyoloji Kliniği, Ankara, Türkiye

${ }^{3}$ Yılıırım Beyazıt Üniversitesi, Ankara Şehir Hastanesi, Çocuk Hastanesi, Çocuk Nöroloji Kliniği, Ankara, Türkiye

\section{Öz}

Amaç: Baș ağrısı çocukluk çağında sık karșılașılan bir yakınmadır. Değerlendirmede görüntüleme yöntemlerine sıklıkla başvurulmaktadır. Bu çalışmada, baş ağrısı ile başvuran çocuklarda görüntüleme yöntemleri ile saptanan bulguların sıklığını saptamak ve baș ağrısında SWI (Susceptibility Weighted Imaging) ve DWI (Difusion Weighted Imaging) sekansların olası gerekliliğine vurgu yaparak Manyetik Rezonans Görüntüleme (MRG)'nin tanıdaki yerininin tartışılması amaçlandı.

Gereç ve Yöntemler: Çalışmaya baş ağrısı yakınması ile başvuran ve MRG yapılan 119 hasta (51 E / 68 K; ortalama 11.63 × 3.69 yıl) dahil edildi. Baş ağrısının başlangıç yaşı, süresi, tipi, atak sıklığı ile hastanın fizik ve nörolojik muayene bulguları kaydedildi. Kranial MRG'de izlenen patolojiler değerlendirildi.

Bulgular: Hastaların 89'unda (\%74.8) primer, 19'unda (\%16) sekonder, 11'inde ise (\%9.2) spesifiye edilemeyen baș ağrısı mevcuttu. MRG yapılan hastaların, \%63.9'unda pozitif görüntüleme bulguları olmakla birlikte bunların çok azı başağrısı semptomunu açıklayıcı intrakraniyel bir patolojiydi (5/76; \%6.5). En sık rastlanan pozitif bulgu sinüzitti (46/76; \%61). SWI görüntülerde 2 hastada gelişimsel venöz anomali, 1 hastada kavernom tespit edildi. DWI görüntülerde ise hiçbir hastada patolojik bulgu saptanmadı. Baș ağrısının tipinin, atak süresinin, cinsiyetin, yașın MRG'de patoloji tespit edilme oranını anlamlı şekilde değiştirmediği görüldü. Buna karşın atak süresi, ek patoloji varlığı anlamlı bulundu. Klinisyenin gerekli görmesi sonucu veya muayene bulgusu olduğu için tetkik edilenlerde MRG'de patoloji tespit edilme oranı, aile anksiyetesi sebebiyle tetkik edilenlerden anlamlı şekilde yüksek bulundu.

Sonuç: Çocukluk çağında bașağıısı varlığında MRG anormal nörolojik muayene bulguları olan hastalara önerilmeli diğer hastalarda görüntüleme öncesi ayrıntıı klinik değerlendirme gerekirse Kulak Burun Boğaz'ı de içeren konsültasyonlarla birlikte yapılmalıdır. MRG'ye SWI ve DWI sekansların eklenmesinde potansiyel yarar vardır. Son olarak ailelerin endișesi MRG istemi yapmak için bir endikasyon olmamalıdır.

Anahtar Sözcükler: Baş ağrısı, Çocuk, Manyetik Rezonans Görüntüleme, MRG

\section{ABSTRACT}

Objective: Headache is a common complaint in childhood. Imaging methods are frequently used in evaluation. This study aimed to determine the frequency of findings detected by imaging methods in children presenting with

(1)

EKŞIOĞLU AS: 0000-0002-7044-5270 UÇAN B : :0000-0002-2109-139X
Çıkar Çatışması / Conflict of Interest: Tüm yazarlar adına, ilgili yazar çıkar çatışması olmadığını belirtir.

Etik Kurul Onayı / Ethics Committee Approval: Bu çalıșma Helsinki Deklarasyonu Illkelerine uygun olarak yapılııștı. Çalıșmamız Dr. Sami Ulus Kadın Doğum, Cocuk Sağlı̆ı ve Hastalıkları Eğitim ve Araștırma Hastanesi Klinik Araștırmalar Etik Kurulu tarafindan 3 Haziran 2021 tarihinde E-21/06-176 saylı etik kurul kararı ile onaylanmış̧ır.

Yazarların katkısı / Contribution of the Authors: EKŞioĞLU AS: Araștırma ve/veya makalenin hipotezini veya fikrini olușturan, Sonuçlara ulașmak için planlama/ metodoloji belirleme, Araştırma/çalışmanın sorumluluğunu üstlenmek, ilerlemenin seyrini denetlemek, Hasta takibinde sorumluluk almak, ilgili biyolojik malzemelerin toplanması, veri yönetimi ve raporlama, deneylerin yürütülmesi, Sonuçların mantıksal olarak Yorumlanması ve sonuçlandıııması, Çalıșma için gerekli literatür taramasında sorumluluk almak, Calıșmanın bütününün veya önemli bölümlerinin yazımında sorumluluk almak, Yazım ve dilbilgisi dıșında bilimsel olarak gönderilmeden önce makaleyi gözden geçirme. UÇAN B: Araștırma ve/veya makalenin hipotezini veya fikrini olușturan, Sonuçlara ulașmak için planlama/metodoloji belirleme, Araștırma/çalıșmanın sorumluluğunu üstlenmek, ilerlemenin seyrini denetlemek, Hasta takibinde sorumluluk almak, ilgili biyolojik malzemelerin toplanması, veri yönetimi ve raporlama, deneylerin yürütülmesi, Sonuçların mantıksal olarak Yorumlanması ve sonuçlandıııması, Çalışma için gerekli literatür taramasında sorumluluk almak, Çalışmanın bütününün veya önemli bölümlerinin yazımında sorumluluk almak, Yazım ve dilbilgisi dışında bilimsel olarak gönderilmeden önce makaleyi gözden geçirme. CEYLAN N: Araștırma ve/veya makalenin hipotezini veya fikrini olușturan, Sonuçlara ulașmak için planlama/metodoloji belirleme, Araștırma/çalıșmanın sorumluluğunu üstlenmek, ilerlemenin seyrini denetlemek, Hasta takibinde sorumluluk almak, ilgili biyolojik malzemelerin toplanması, veri yönetimi ve raporlama, deneylerin yürütülmesi, Sonuçların mantıksal olarak Yorumlanması ve sonuçandıııması, Calıșma için gerekli literatür taramasında sorumluluk almak, Çalıșmanın bütününün veya önemli bölümlerinin yazımında sorumluluk almak, Yazım ve dilbilgisi dışında bilimsel olarak gönderilmeden önce makaleyi gözden geçirme.

Atıf yazım șekli / How to cite : Seçiloğlu A, Uçan B ve Ceylan N. Çocukluk Çağı Baș Ağrılarında Kranial Manyetik Rezonans Görüntülemenin Tanısal Değeri. Türkiye Çocuk Hast Derg 2021;15:420-426.
Yazıșma Adresi / Correspondence Address:

\section{Ayşe Seçil EKŞioĞLU}

Sağlık Bilimleri Üniversitesi, Ankara Sehir Hastanesi,

Çocuk Radyoloji Kliniği, Ankara, Türkiye

E-posta: yucelsecil@yahoo.com
Geliş tarihi/ Received : : 23.08.2021 Kabul tarihi / Accepted : 14.09.2021 Elektronik yayın tarihi : 15.09 .2021 Online published

DOI: 10.12956/tchd.986112 
headache and to discuss the importance of Magnetic Resonance Imaging (MRI) in diagnosis by emphasizing the possible necessity of SWI (Susceptibility Weighted Imaging) and DWI (Difusion Weighted Imaging) sequences in headache.

Material and Methods: 119 patients (51 M/68 F; mean 11.63 \pm 3.69 years) who presented with headache and underwent MRI were included in the study. The age of onset, duration, type, frequency of attacks, physical and neurological examination findings of the patient were recorded. Pathologies observed in cranial MRI were evaluated.

Results: Headache was primary in 89 (74.8\%) patients, secondary in 19 (16\%), and unspecified headache in 11 (9.2\%) patients. Although $63.9 \%$ of patients who underwent MRI had positive imaging findings, very few of them were intracranial pathology explaining the headache symptom (5/76; 6.5\%). The most common positive finding was sinusitis (46/76; 61\%). Developmental venous anomaly was detected in 2 patients and cavernoma was detected in 1 patient on SWI images. No pathological finding was detected in any of the patients on DWI images. It was observed that the type of headache, duration of attack, gender and age did not significantly change the rate of pathology detected in MRI. On the other hand, the duration of the attack and the presence of additional pathology were found to be significant. The rate of of pathology in MRI was found to be significantly higher in patients who were examined due to clinical findings or due to examination findings, compared to those who were examined due to family anxiety.

Conclusion: In the presence of headache in childhood, MRI should be recommended to patients with abnormal neurological examination findings, and in other patients, a detailed clinical evaluation before imaging should be performed together with consultations including otorhinolaryngology. There is potential benefit in adding SWI and DWI sequences to MRI. Finally, parents concern should not be an indication for an MRI request.

Key Words: Headache, Child, Magnetic Resonance Imaging, MRI

\section{GiRiș}

Baş ağrısı çocukluk çağında sık karşılaşılan bir yakınma olup sıklığı \%25 ila \%93 arasında değişmektedir (1). Çocukluk çağında görülen baş ağrılarının büyük çoğunluğu organik nedenlere bağlı olmayan primer başağrıları olarak sınılandırılan grupta olup migren ve gerilim tipi başağrılarıdır. Sekonder tip baş ağrısı ise sinir sistemini veya diğer sistemleri ilgilendiren hastalıklarla ilişkili olarak ortaya çıkar. Bu grup içinde intrakranial kitle, kanama, enfeksiyon veya kafa içi basınç artışı gibi ciddi organik durumlar yer alır. Sekonder baş ağrıları hastanın hayatını tehdit eden hastalıklar için önemli bir ipucu olabileceğinden tanınmaları önemlidir. Üçüncü bir tipi de sınıflandırılamayan başağrıları oluşturmaktadır (2).

Her ne kadar 2002'de yayınlanan Amerikan Nöroloji Akademisi ve Çocuk Nöroloji Derneği Alt Komitesi Kalite Standardları (Quality Standards Subcommittee of the American Academy of Neurology and the Practice Committee of the Child Neurology Society) tavsiyesine göre tekrarlayan başağrıları olan ancak normal nörolojik muayenesi bulunan çocuklara nörogörüntüleme yapılması önerilmese de klinikte rutin uygulama bu yönde değildir (3-5). Ebeveynlerin altta yatan ciddi bir hastalık korkusuyla ileri tetkik taleplerinin artması nedeniyle, klinisyenler baş ağrısı olan çocukların ilk değerlendirilmesi sırasında görüntülemeyi yaygın olarak kullanmaktadır. Bununla birlikte, baş ağrısı nedeni ile kesitsel inceleme istenen hastaların sadece \%1.2'sinde etyolojiyi açıklayacak ve tedavi gerektirecek anormallikler gözlenebilirken \%25'inde kranial MRG'de insidental bulgular saptanmaktadır (6). Bu durum hastalar ve ebeveynleri rahatlatmak yerine daha endişeli hale getirebilir.

Bu çalışmada, baş ağrısı şikayeti ile nedeniyle nöroloji polikliniğine başvuran çocuklardaki baş ağrılarının klinik özelliklerini değerlendirmeyi ve görüntüleme ile saptanan intrakraniyal bulguların sıkığını ve baş ağrısı tanısında SWı ve
DWI sekansların olası gerekliliğine vurgu yaparak kranial MR görüntülemenin yerini tartışmayı amaçladık.

\section{GEREÇ ve YÖNTEMLER}

Çalışmamız Dr. Sami Ulus Kadın Doğum, Çocuk Sağlığı ve Hastalıkları Eğitim ve Araştırma Hastanesi Klinik Araştırmalar Etik Kurulu tarafından 3 Haziran 2021 tarihinde E-21/06-176 sayılı etik kurul kararı ile onaylanmıştır.

Çalışmaya Ocak 2019- Mart 2020 tarihleri arasında, hastanemizin çocuk nöroloji polikliniğine baş ağrısı yakınması ile başvuran ve kranial MR inceleme yapılan yaşları 3 ile 18 arasında değişen 119 hasta (51 erkek; 68 kı) dahil edildi. Hastaların hastane bilgi sistemindeki anamnez, muayene verileri taranarak toplandı. Daha önce kesitsel kranial inceleme yapılarak baş ağrısına neden olan intrakraniyal patolojisi bilinen hastalar çalışmaya alınmadı.

Çalışma retrospektif, deskriptif özellikte planlandı ve çocuk nöroloji uzmanı tarafından alınan anamnez bilgileri (baş ağrısının başlangıç yaşı, süresi, atak sıklığı) ile yapılan fizik ve nörolojik muayene bulguları hastane bilgi sisteminden taranarak kaydedildi. Ayrıca, hastaların ek nörolojik veya sistemik hastalık öyküsü ve kullandığı ilaçlar not edildi. Oftalmoloji bölümünce değerlendirilen hastaların göz bulguları ile lomber ponksiyon (LP) yapılan hastaların BOS bulguları değerlendirildi.

Baş ağrısı "International Headache Society" (IHS) kriterleri gözönünde bulundurularak primer, sekonder ve spesifiye edilemeyen baş ağrısı olarak tiplendirildi (7-8). Primer baş ağrısı tanısı sekonder baş ağrısı nedenleri dışlanarak konuldu. Primer baş ağrıları daha sonra migren, gerilim tipi baş ağrısı, küme tipi baş ağrısı ve diğer trigeminal otonom sefaljiler olarak tiplendirildi. Sekonder baş ağrısı olarak başka hastalığa bağlı baş ağrısı nedenleri kabul edildi. Hem primer hem sekonder 
başağrısı tanımına uymayan baş ağrısı spesifiye edilemeyen başağrısı olarak kabul edildi.

Amerikan Nöroloji Akademisi ve Çocuk Nöroloji Derneği Alt Komitesi ani başlangıçlı baş ağrısı, ağrısı paterninde değişiklik, fokal nörolojik muayene bulguları, artmış kafa içi basıncı bulguları, bilinç değişikliği ve baş ağrısına nöbetlerin eşlik etmesi durumunda kranial görüntüme yapılmasını önermektedir (2). Hastaların bir kısmına bu endikasyonlara sadık kalınarak kranial MRG yapıldı.

Bulguları olan bu gruptaki hastalardan 5'ine hızı sonuç alabilmek adına MRG öncesinde Bilgisayarlı Tomografi (BT) inceleme de yapıldı. Ayrıca, bu endikasyonların olmadığı bazı hastalara hasta yakınlarının altta yatabilecek hastalıklar ve özellikle de beyin tümörü açısından yoğun endişesi nedeniyle, yine bazı hastalara da klinisyen isteği ile kranial görüntüleme gerçekleştirildi.

Kranial BT incelemeleri Brilliance CT 64 Chanel ;Philips,France, kraniyal MRG incelemeleri Magnetom Essenza 1.5T; Siemens AG, Germany cihazları ile yapıldı. Kranial MR görüntülemede aynı standart protokol uygulandı. T1 ağırlıklı spin eko aksiyal planda, turbo spin eko T2 ağırlıklı aksiyal ve koronal planda ve fast fluid -attenuated inversion recovery (FLAIR) ağılıkı imajlar alındı. Ayrıca bu sekanslara SWI ve DWI sekansları eklendi.

PACS sisteminde kayıtlı olan kranial BT ve MR görüntüleri pediatrik nöroradyolojide 10 yıldan uzun süreli deneyimi olan bir çocuk radyoloğu tarafından yeniden değerlendirildi.

\section{Beyin BT ve MRG'de görülen patolojiler 5 gruba ayrıldı:}

1. Baş ağrısına neden olan kranial patolojiler (intrakranial tümör, hidrosefali vs.)

2. Klinik önemi olan ancak insidental olarak saptanan kranial patolojiler (Chiari malformasyonları, araknoid kistler vs.)

3. Klinik önemi olmayan ve insidental olarak saptanan kranial patolojiler (nonspesifik beyaz cevher intensiteleri, milimetrik gliozis odakları, periventriküler lökomalazi (PVL) vs.)

4. Baş ağrısına neden olan ekstrakranial patolojiler (sinüzit, mastoidit vs)

Insidental olarak görülen ekstrakranial patolojiler sınıflamaya dahil edilmedi.

Asemptomatik olup ileri tetkike gerek olmayan, kavum septum pellisidum, sisterna magna ve ventriküler asimetri gibi anatomik varyasyonlar anormal bulgu olarak kabul edilmedi.

Kranial MR'daki anormal bulgularının sıklığı ve baş ağrısı tipi ile ilişkisi değerlendirildi. SWI ve DWI sekansların tanıya katkısı değerlendirildi. Doğru endikasyonla MR çektiren hastalar ile hasta yakınlarının endişelerinden dolayı çekilen MRG'lerdeki anormallikler karşılaştırıldı.

Verilerin değerlendirimesinde Package for Social Sciences (SPSS), Windows 20 için (IBM SPSS Inc., Chicago, IL) programı kullanılmıştır. Verilerin normal dağılımı KolmogorovSmirnov testi ile incelenmiştir. Sayısal değişkenler yüzdelerle ifade edilmiştir. Değişkenlerin büyük çoğunluğu normal dağılım göstermediğinden analizlerde nonparametrik testler kullanılmıştır. MRG'de patoloji olup olmaması durumu ile değişkenlerin farklılığı Ki-kare testi ile değerlendirilmiştir. $\mathrm{P}<0.05$ değeri istatistiksel anlamlılık için eşik değer olarak belirlenmiştir.

\section{BULGULAR}

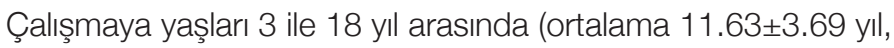
ortanca yaș 12) 119 hasta alındı. Hastaların 68'i (\%57.1) kız, 51 'i (\%42.9) erkek olup kı//erkek oranı 1.65'tir.

Hastaların 11 tanesinin sistemik muayene bulgusu bilgisine ulaşılamamıştır. Sistemik muayene bulgusu olan 108 hastanın 107'sinin (\%99) sistemik muayene bulguları normal iken, 1 (\%1) hastada hipertansiyon tespit edildi.

Hastaların 108'inde (\%90.8) nörolojik ve göz muayenesi yapıımış, 11 'inde (\%9.2) ise yapılımamıştır.

Verilerine ulaşılan 108 hastanın 106'sının (\%98.1) nörolojik ve göz muayene bulguları normal, 2'sinin (\%1.9) anormal olup papil ödem tespit edilmiştir.

11 hastanın LP geçmişine dair veri elde edilememiştir. Verisi bulunan 108 hastanın 2'sine (\%1.9) LP yapılmış, 106'ına (\%98.1) yapılmamıştır. LP yapılan hastaların bulguları normal olarak saptanmıştır.

Tablo I: Başağrısı ile Başvuran Çocuklarda MRG patolojlerinin Dağıımı.

\begin{tabular}{|c|c|c|c|}
\hline Pataoloji & $\begin{array}{l}\text { Hasta } \\
\text { Sayısı }\end{array}$ & $\begin{array}{c}\text { Patoloji } \\
\% \\
\end{array}$ & $\begin{array}{l}\text { Patoloji } \\
\text { Tipi }^{*}\end{array}$ \\
\hline Sinüzit & 46 & $\% 61$ & 4 \\
\hline Parsiyel emty sella & 6 & $\% 7.9$ & 2 \\
\hline Atrofi & 3 & $\% 3.9$ & 2 \\
\hline $\begin{array}{l}\text { Gelişimsel venöz anomali/ } \\
\text { kavernom }\end{array}$ & 3 & $\% 3.9$ & 2 \\
\hline Araknoid Kist & 3 & $\% 3.9$ & 2 \\
\hline PVL & 2 & $\% 2.6$ & 3 \\
\hline Psödotümör serebri & 2 & $\% 2.6$ & 1 \\
\hline Otomastoidit & 2 & $\% 2.6$ & 4 \\
\hline Non spesifik glial sinyaller & 2 & $\% 2.6$ & 3 \\
\hline Inferior vermis hipoplazi & 2 & $\% 2.6$ & 2 \\
\hline Intrakranial kitle & 1 & $\% 1.3$ & 1 \\
\hline Vaskülit & 1 & $\% 1.3$ & 1 \\
\hline Hidrosefali & 1 & $\% 1.3$ & 1 \\
\hline Chiari Tip 1 & 1 & $\% 1.3$ & 2 \\
\hline $\begin{array}{l}\text { Sessiz lakün, iskemik } \\
\text { değişiklik }\end{array}$ & 1 & $\% 1.3$ & 3 \\
\hline Toplam & 76 & $\% 100$ & En sik: 4 \\
\hline
\end{tabular}

*Materyal Metodda belirtilen BT-MRG patoloji klasifikasyonuna göre: 1. Baş ağrısına neden olan kraniyal patolojiler, 2.Klinik önemi olan ancak insidental kraniyal patolojiler, 3. Klinik önemi olmayan, insidental kraniyal patolojiler, 4. Baş ağrısına neden olan ekstrakranial patolojiler. 
Tablo II: MR'da Patoloji Görülme Sıklığını Çeşitli Faktörlerle Değişimi.

\begin{tabular}{|c|c|c|c|}
\hline Parametre & Sayı (\%) & MR'da Patoloji Varlığı Sayı (\%) & $\mathbf{p}$ \\
\hline $\begin{array}{l}\text { Cinsiyet } \\
\text { KIz } \\
\text { Erkek }\end{array}$ & $\begin{array}{l}68(\% 57.1) \\
51(\% 42.9)\end{array}$ & $\begin{array}{l}42(\% 61.7) \\
34(\% 66.6)\end{array}$ & $p>0.05$ \\
\hline $\begin{array}{l}\text { Yaş } \\
<10 \text { yaş } \\
>10 \text { yaş }\end{array}$ & $\begin{array}{l}44(\% 37) \\
75(\% 63)\end{array}$ & $\begin{array}{c}32(\% 72) \\
44(\% 59)\end{array}$ & $p>0.05$ \\
\hline Ağrı Süresi & $\begin{array}{c}10.59 \pm 10.27 \text { (ort) } \\
>24 \text { saat }\end{array}$ & $\begin{array}{c}70(\% 92) \\
6(\% 8)\end{array}$ & $p>0.05$ \\
\hline Atak Sayısı & $\begin{array}{l}5.61 \pm 8.4 \text { (ort) } \\
30 \text { /ay hergün }\end{array}$ & $\begin{array}{l}65 \text { (\%61.1) } \\
11(\% 100)\end{array}$ & $\mathrm{p}<0.05$ \\
\hline $\begin{array}{l}\text { Başağrısı Çeşidi } \\
\text { Primer } \\
\text { Sekonder } \\
\text { Nonspesifiye }\end{array}$ & $\begin{array}{c}89(\% 74.8) \\
19(\% 16) \\
11(\% 9.2)\end{array}$ & $\begin{array}{c}56(\% 62.9) \\
14(\% 73.6) \\
6(\% 54.5)\end{array}$ & $p>0.05$ \\
\hline $\begin{array}{l}\text { Ek Hastalık } \\
\text { Var } \\
\text { Yok }\end{array}$ & $\begin{array}{l}28(\% 23.5) \\
91(\% 76.5)\end{array}$ & $\begin{array}{l}22(\% 78.5) \\
54(\% 59.3)\end{array}$ & $\mathrm{p}<0.05$ \\
\hline $\begin{array}{l}\text { İstem Endikasyonu } \\
\text { Gerçek End } \\
\text { Klinisyen Tercihi } \\
\text { Aile endişesi }\end{array}$ & $\begin{array}{l}52(\% 43.6) \\
43(\% 36.1) \\
24(\% 20.1)\end{array}$ & $\begin{array}{c}33(\% 63.4) \\
31(\% 72) \\
3(\% 12.5)\end{array}$ & $\mathrm{p}<0.05$ \\
\hline
\end{tabular}

Hastaların 89'unda (\%74.8) primer, 19'unda (\%16) sekonder, 11 'inde ise (\%9.2) spesifiye edilemeyen baş ağrısı mevcuttur. Primer ağrı tipi verisine ulaşılabilen 25 hasta mevcuttur. Bu hastaların 18 'inde migren (18/25, \%72), 7 'sinde (7/25, \%28) ise gerilim tipi baş ağrısı tanısı mevcuttur.

Ağrı süresine bakıldığında hastaların ortalama ağrı süresi $10.59 \pm 10.27$ saat olarak bulunmuştur. Ortanca ağrı süresi 3 saattir (min-max. 1-24 saat). Ayllk atak sayısı ortalama 5.61 \pm 8.4 tespit edilmiștir. Ortanca atak sayısı ayda 15 (min-max, 1-31)'dir.

Hastalann 28'inde (\%23.5) ek hastallk mevcudiyetine rastlanmaktadir. 91 'inde (\%76.5) ise ek hastalık mevcut değildir. Inceleme öncesinde anamnezde belirtildiği üzere; hastaların 7'sinde (\%5.9) epilepsi, 1'inde (\%0.8) lösemi, 1 'inde (\%0.8) konjenital kalp hastalı̆̆ı, 1'inde (\%0.8) IGG4 aracılıklı vaskülit, 1'inde (\%0.8) psödotümör serebri, 4'ünde (\%3.4) kaygı bozukluğu, 1'inde (\%0.8) obezite, 4'ünde (\%3.4) sinüzit, 1'inde (\%0.8) aplastic anemi, 1 'inde (\%0.8) ensefalit, 1 'inde (\%0.8) turner sendromu, 1 'inde (\%0.8) arteriovenöz malformasyon, 1'inde (\%0.8) konjenital hidrosefali, 1 'inde (\%0.8) hipertansiyon mevcuttur. 93 hastanın (\%78.1) ise hastalık verisi mevcut değildir.

Kullanılan ilaçlara bakııdığında 99 hastanın ilaç verisi yoktur (\%83.2). 6 hasta (\%5) antidepresan, 1 hasta (\%0.8) diazomid, 5 hasta (\%4.2) antiepileptic, 5 hasta (\%4.2) antibiyotik, $1 \mathrm{i}$ hasta (\%0.8) brufen, 1 hasta (\%0.8) sibelium, 1 hasta (\%0.8) enapril kullanmaktadır.

Hastaların 5'ine (\%4.2) MR incelemenin yanısıra kranial BT tetkiki yapılmış, 114'üne (\%95.8) yapılmamışıır. BT tetkiki yapılan tüm hastalarda patoloji bulunmuştur. Bu hastaların 4'ünde $(4 / 5$, \%80) sinüzit, 1'inde (1/5) intrakranial kitle saptanmıștır.
Hastaların tümüne MR tetkiki yapılmıştır. Hastaların 76'sında (\%63.9) MRG'de patoloji tespit edilmiş, 43'ünde ise (\%36.1) edilmemiștir. MRG'de izlenen patolojlerin dağlımı Tablo I'de özetlenmiștir.

BT incelemesi de bulunan sadece 1 hastada malign özellikte intrakranial kitle saptanırken, çoğu bulgu insidental ekstrakranial özelliktedir ve bunların çoğunluğunu da sinüzit olușturmaktadır (Resim 1,2).

SWI görüntülerde 3 hastada (\%2.5) ek patoloji izlenmiş olup bu hastaların 2'sinde gelişimsel venöz anomali 1'sinde kavernom izlenmiștir (Resim 3). 115 hastada ise (\%97.5) SWI görüntülerde patoloji saptanmamıştır. DWI görüntülerde ise hiçbir hastada patolojik bulgu saptanmamıştır.

Hastalara MRG tetkiki yapılma sebeplerine bakıldığında, nedenlerin 52'si (\%43.6) hastada anormal muayene bulgusu olması, 43'ü (\%36.1) klinisyenin gerekli görmesi, 24 hastada (\%20.1) ise aile anksiyetesi/aile ısrarı tespit edilmiștir.

Cinsiyetler arasında MRG'de patoloji tespit edilme oranları arasında fark yoktur. Kızlarda patoloji tespit edilme oranı, 42/68 (\%61.7); erkeklerde ise 34/51 (\%66.6)'dır (p>0.05).

Hastalar her iki yaş grubunun da anlamlı sayıda katılımcı içermesi gözetilerek, 10 yaş altı ve 10 yaş üstü olmak üzere iki gruba ayrımışıtı. Bu iki grup arasında MRG'de patoloji tespit edilme oranları benzer bulunmuștur. 10 yașından küçükler ve 10 yaşındakilerde patoloji tespit oranı, 32/44 (\%72.7), diğer grupta ise 45/75 (\%60) bulunmuştur ( $p>0.05$ ).

Ağrı süresi ile MRG'de patoloji tespit edilme oranları arasında anlamlı bir ilișki bulunamamıștır ( $p>0.05$ ). 


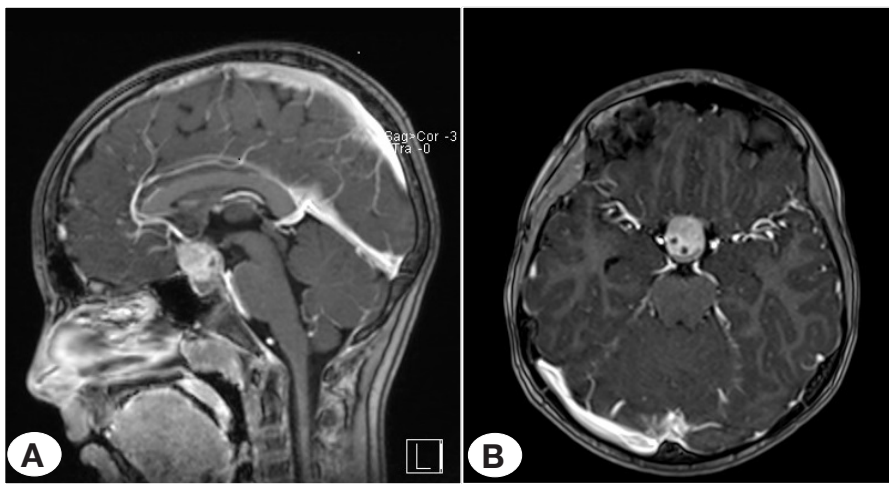

Resim 1: A) Bașağrısı ile bașvuran ve anormal göz ve nörolojik muayene bulguları olan hasta. B) Sagittal ve B. aksiyel kontrastlı T1 ağılıklı kraniyal MR görüntülerinde suprasellar yerleşim gösteren ve iyi kontrastlanan kraniofaringioma izleniyor.

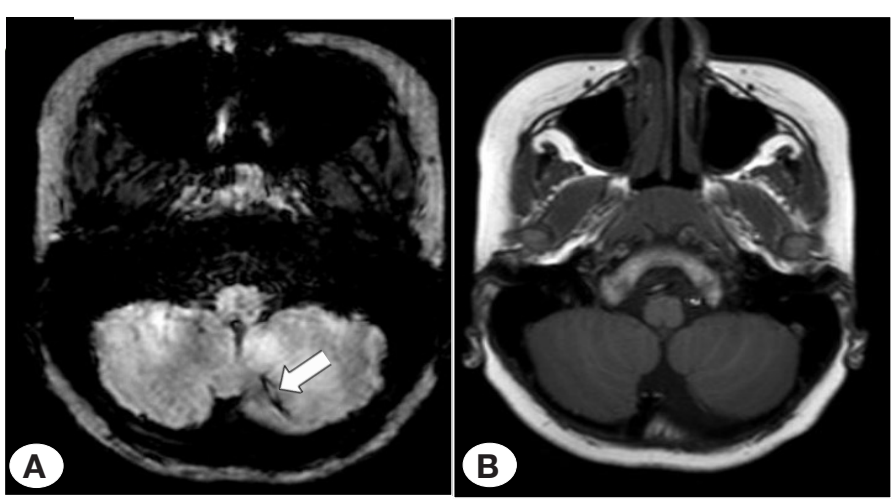

Resim 3: A) Aksiyel SWI görüntüde sol serebellar hemisferdeki gelişimsel venöz malformasyon görülmektedir (beyaz ok). B) B. SWI incelemede izlenen gelişimsel venöz anomali T1A aksiyel görüntüde görülmemektedir.

Aylık atak sayısı, hergün/ayda 30 gün olanlarda, MRG'de patoloji tespit edilme oranı \%100 (11/11) olarak bulunmuştur. Bu oran diğer atak sayısına sahip olanlardan \%61.1 (66/108) anlamlı şekilde yüksektir ( $p<0.05)$.

Baş ağrısının çeşidi de MRG'de patoloji tespit edilme oranını anlamlı șekilde değiștirmemektedir (p>0.05). Primer baș ağrısı olanlarda MRG'de patoloji tespit oranı, 56/89 (\%62.9); sekonder olanlarda, 14/19 (\%73.6), spesifiye edilemeyen grubunda ise 6/11 (\%54.5) bulunmuştur.

Ek hastalık varlığı, MRG'de patoloji tespit edilme oranını anlamlı șekilde arttırmaktadır ( $\mathrm{p}<0.05)$. Ek hastalığı olanlarda MRG'de patoloji tespit edilme oranı, 22/28 (\%78.5) iken ek hastalığı olmayanlarda 54/91 (\%59.3)' tür.

MRG tetkik edilme sebebi ile MRG'de patoloji tespit edilme oranı kıyaslandığında, klinisyenin gerekli görmesi sonucu tetkik edilenler ve muayene bulgusu olduğu için tetkik edilenlerde patoloji tespit edilme oranı, aile anksiyetesi sebebiyle tetkik edilenlerden anlamlı şekilde yüksektir $(p<0.05)$. Bu oran klinisyenin gerekli görmesi sonucu tetkik edilenlerde, 31/43 (\%72), muayene bulgusu olduğu için tetkik edilenlerde 33/52

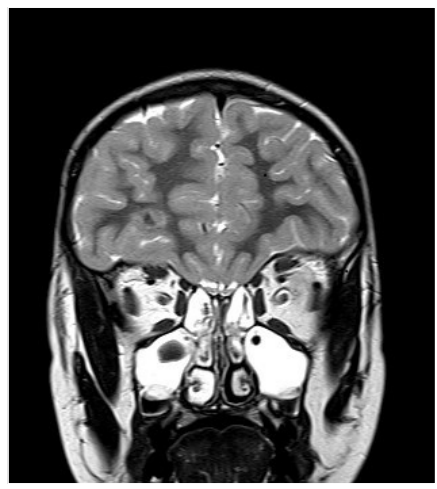

Resim 2: Koronal T2A görüntüde bilateral maksiller sinüs ve etmoid hücrelerin duvarlarında mukozal kalınlaşma ve Sıvı intensiteleri izlenmektedir. Bulgular sinüzit ile uyumlu olarak değerlendirilmiştir.

(\%63.4) aile anksiyetesi sebebiyle tetkik edilenlerde ise 3/24 (\%12.5) bulunmuştur.

MR'da patoloji görülme sıklığının çeşitli faktörlerle değişimi Tablo Il'de özetlenmiştir.

\section{TARTIŞMA}

Hem yetişkin yaş grubunda hem de çocuklarda başağrısı sık rastlanan bir semptom olup etyolojiyi araştırmak için görüntülemeye sıklıkla başvurulmaktadır. Başağrısı nedeni ile nörogörüntüleme yapılan çocuklardaki kranial ve ekstrakranial bulgular erişkin popülasyonundaki kadar iyi dokümente edilmiş değildir

Çocuklarda baş ağrısının en sık nedeni migren ve gerilim tipi baş ağrısıdır (9-10). Bizim çalışmamızda da literatürle uyumlu olarak en sık görülen baş ağrısı nedeni migren ardından da gerilim tipi baş ağrısı olarak saptanmış olup olguların yaklaşık \%75'ine primer tip başağrısı, bunların da \%72'sinde migren tanısı konmuştur. Hastaların \%16'sında sekonder başağrısı mevcut olup bunların da çoğunluğu sinüzite bağlıdır. Literatürde de baş ağrısı nedeniyle görüntülenen hastaların \%1 ile 13'ünde sinüs hastalıkları raporlanmıştır $(11,12)$. Çalışmamızda primer baş ağrısı olan hastaların 27' inde (\%30) sinüzitin ağrının karakterinin ve yoğunluğunu değişmesinden sorumludur. Literatürde çocuklarda "tanımlanmamış" baș ağrısı oranı tüm baş ağrılarının \%5.6 ila \%23.4 ünü oluşturmaktadır. Bizim çalışmamızda bu oran \%11'di.

Çalışmamızda MR incelemenin yanısıra hastaların az bir kısmına hızlı sonuç elde etme amacıyla beyin BT de yapılmıștır (5/119; / \%4.2). BT tetkiki yapılan hastaların \%80'inde, MRG yapılan hastaların, \%63.9'unda pozitif görüntüleme bulguları olmakla birlikte bunların çok az bir kısmı başağrısı semptomunu açıklayıcı intrakranial bir patolojidir (5/76:\%6.5). Başağrısını açıklayabilecek en yaygın patolojiler ekstrakraniyal insidental özellikte olup 46/76: \%61'ini sinüzit, ardından da 2/76: \%2.6 ile mastoidit takip etmektedir. 
Bizim çalışmamızda da olduğu gibi sinüzit başta olmak üzere Kulak Burun Boğaz (KBB) hastalıkları baş ağrısı nedenlerinin büyük kısmını oluşturmaktadır. Bu hastalıklar kolaylıkla tanınan, tedavi edilebilen ve medikal tedaviye yanıtın hızlı olduğu hastalıklardır. Bu nedenle baș ağrısı değerlendirilmesinde bizce MRG öncesi mutlaka KBB değerlendirilmesi yapılmalı, gereksiz istemlerin önüne geçilmelidir.

Mevcut klavuzlara göre, tekrarlayan veya normal bir nörolojik muayenesi olan baş ağrilı çocuklarda nörogörüntüleme rutin olarak endike değildir. Ancak günlük klinik uygulamada, nörogörüntüleme sadece anormal nörolojik bulguları olan hastalarda intrakranial bir patolojiyi dışlamak için değil, aynı zamanda ebeveyn anksiyetesi ya da normal nörolojik muayenesi olan intrakranial tümör vakaları gibi altta yatan bir durumu kaçırma endişesiyle defansif olarak da fazlaca talep edilmektedir. Çocukluk çağında beyin tümörleri nadirdir. (3-5 / 100 000) ve beyin tümörü olan 10 çocuktan sadece birinde nörolojik ve fiziksel muayene normal iken baş ağrısı mevcuttur (13). 16 çalışmadan oluşan bir meta analizde nörolojik muayenesi normal olan ve opsiyonel ve araşırıma amaçlı MRG yapılan 19.559 hastanın 135 'inde (0.70\%) insidental neoplastik lezyon saptanmıștır (14). Bizim serimizde baș ağrısı nedeniyle görüntülene 119 hastanın yalnız birinde malign tümör bulundu. Dahası normal nörolojik muayenesi olan hiçbir hastada beyin tümörü saptanmadı.

Çalışmamızda kılavuzlardaki koşulları karşılaması ya da klinisyenin gerekli görmesi sonucu tetkik edilenlerde patoloji tespit edilme oranı, aile anksiyetesi sebebiyle tetkik edilenlerden anlamlı şekilde yüksek bulunmuştur ( $p=0.03$ ). Bu bize hasta yakını anksiyetesinin MR çekilme endikasyonu olmaması gerektiğini bir kez daha göstermektedir.

Bu çalıșmada hastaların aylık atak sayısı ve ek hastalığa sahip olmaları MRG'de patoloji sıklığını artıran anlamlı parametreler olarak karşımıza çıkmakta olup atak sayısı bir ay boyunca 30 (her gün) olan hastaların hepsinde görüntülemede patoloji tespit edilmiștir. Diğer yandan ek hastalık varlığı da patolojik görüntüleme bulgusu olasilığını artırmakta olup bu hastalarda da nörogörüntülemeye gidilebilir. Bu çallşma cinsiyet, yaş, atak süresi ya da başağrısı tipinin pozitif bulgu sıklığına etkisi olmadığını göstermiştir.

Yapılan çalışmalarda baş ağrilı çocuklarda MRG'de modern sekansların kullanılması ile anormal bulguların daha yüksek (\%52.8) insidans ile bulunduğu gösterilmiştir $(15,16)$.

SWI MRG; temeli GRE (gradient echo) MRG'ye dayanan,kan ürünleri, deoksihemoglobin, kalsiyum, demir gibi diamanyetik ve hemosiderin gibi paramanyetik maddeleri saptamada son derece yüksek hassasiyete sahip olan bir sekanstır. Bu nedenle pediatrik nöro- görüntülemede son yıllarda sık kullanılmaktadır. Çalıșmamızda tüm hastalarda rutin MR sekanslarına SWI sekansı eklenmiștir. Bu sekansta 2 hastamızda konvansiyonel görüntülemede net izlenemeyen gelişimsel venöz malformasyon, 1 hastamızda ise kavernom varlığı gösterilmiş olup diğer hastalarda normal bulgular saptanmıştır.

SWI sekansı ön tanıda baş ağrısı etyolojisinde yer alan intrakranial kanama, travmatik beyin hasarı, serebral vasküler malformasyonlar, inme, sinüs ven trombozu var ise mutlaka rutin sekanslara eklenmelidir. Bunun dıșında çalıșmamızda olduğu gibi baș ağrısında MRG'de rutin sekanslar yanında tanıya katkısı azdır.

Difüzyon ağılıklı görüntüleme (DWI), kontrast madde gerektirmeyen oldukça hızı bir görüntüleme yöntemi olup bașta akut serebral iskemi tanısında olmak üzere intrakranial enfeksiyonlar, neoplazm, travmatik beyin zedelenmesi, demiyelinizan hastalıklar dahil birçok serebral hastalık hakkında önemli bilgiler vermektedir. Çalışmamızda DWI görüntülerde hastalarda herhangi bir patoloji saptanmamıştır. Ancak baş ağrısı sebebi olabilecek yukarıda sayllan birçok hastalık nedeniyle mutlaka konvansiyonel MR incelemesinin tamamlayıcıs olarak kullanılmalıdır.

Bu çalışmanın başıca kısıtlıı̆ı, geriye dönük olarak hasta dosyası incelemesi olup bazı hastaların kayıtlarına tam olarak ulașilamamasına neden olmuștur. Bununla birlikte kranial MRG istenen tüm bașağrısı semptomlu hastalara genel bir ıșık tutmasından dolayı kıymetlidir.

\section{SONUÇ}

Beyin lezyonlarının tanısında kesitsel nöro-görüntülemenin yüksek etkinliği olsa da, yüksek maliyetleri ve BT'deki radyasyonun potansiyel tehlikeleri nedeniyle illk tanı yöntemi olarak kullanılmamalıdılar. Görüntülemede acil durumlar haricinde SWI ve DWI sekanslarını da içeren MRG tercih edilmeli ve öncelikle anormal nörolojik muayene bulguları olan hastalara önerilmeli; diğer hastalarda görüntüleme öncesi ayrıntılı klinik değerlendirme gerekirse KBB'yi de içeren konsültan hekimlerle yapılmalıdır. Ailelerin endișesi MRG için bir endikasyon teșkil etmemelidir.

\section{KAYNAKLAR}

1. Yılmaz Ü, Çeleğen M, Yılmaz TS, Gürçınar M, Ünalp A. Childhood Headaches and Brain Magnetic Resonance Imaging Findings. Eur J Paediatr Neurol 2014;18:163-70.

2. Dao JM, Qubty W. Headache Diagnosis in Children and Adolescents. Curr Pain Headache Rep 2018;22:17.

3. Lewis DW, Ashwal S, Dahl G, Dorbad D, Hirtz D, Prensky A, et al. Practice Parameter: Evaluation of Children and Adolescents with Recurrent Headaches: Report of the Quality Standards Subcommittee of the American Academy of Neurology and The Practice Committee of the Child Neurology Society. Neurology 2002 27;59:490-8. 
4. Pektezel MY, Konuskan B, Sonmez FM, Oguz KK, Anlar B. Pediatric Headache and Neuroimaging: Experience of Two Tertiary Centers. Childs Nerv Syst 2020;36:173-7.

5. Sarma A, Poussaint TY.Neuroimaging. Indications and Imaging Modality of Choice in PediatricHeadache. Clin N Am 2019;29:27189.

6. Gupta SN, Belay B.J. Intracranial Incidental Findings On Brain MR Images in A Pediatric Neurology Practice: A Retrospective Study. Neurol Sci 2008;264:34-7.

7. Headache Classification Subcommittee of the International Headache Society The international classification of headache disorders, 2nd ed. Cephalgia 2004;24:1-151.

8. Olesen J.The International Classification of Headache Disorders, 2nd Edition: Application To Practice. Funct Neurol 2005;20:61-8.

9. Bayram E, Topcu Y,Karaoglu P, Yis U, Cakmakcı Guleryuz H, Hiz Kurul S. Incidental White Matter Lesions in Children Presenting with Headache. Headache 2013;53:970-6.

10. Deda G, Caksen H, Öcal A. Headache Etiology in Children: A Retro-Spective Study of 125 Cases. Pediatr Int 2000;42:668-73.
11. Lewis DW, Dorbad D. The Utility of Neuroimaging in the Evaluation of Children with Migraine Or Chronic Daily Headache Who Have Normal Neurological Examinations. Headache 2000;40:629-32.

12. Alehan FK. Value of Neuroimaging in the Evaluation of Neurologically Normal Children with Recurrent Headache. J Child Neurol 2002;17:807-9.

13. Vazquez-Barquero A, Ibanez FJ, Herrera S, Izquierdo JM, Berciano J, Pascual J. Isolated Headache As The Presenting Clinical Manifestation of Intracranial Tumors: A Prospective Study. Cephalalgia 1994;14:270-2.

14. Morris Z, Whiteley WN, Longstreth WT, Weber F, Lee YC, Tsusuhima Y, et al. Incidental Findings On Brain Magnetic Resonance Imaging: Systematic Review and Meta-Analysis. BMJ 2009;339:b3016.

15. Karaarslan E, Ulus S, Kürtüncü M. Susceptibility-weighted imaging in migraine with aura. AJNR Am J Neuroradiol 2011;32:E5-7.

16. Erin M Fedak, Nicholas A Zumberge, Geoffrey L Heyer. The Diagnostic Role For Susceptibility-Weighted MRI During Sporadic Hemiplegic Migraine. Cephalalgia 2013;33:1258-63. 